\title{
Acute Type C Botulism with Fatal Consequences in a Holstein Breeding Establishment in Northern Italy
}

\author{
Tavella $\mathrm{A}^{1}$, Morosetti G ${ }^{*_{2}}$, Caresia $\mathrm{S}^{2}$, Ciavatta $\mathrm{P}^{3}$, Trevisiol K ${ }^{1}$, Armani $\mathrm{MC}^{1}$, Stifter $\mathrm{E}^{4}$, Piffer $\mathrm{C}^{2}$, Bano L \\ and Lombardo $\mathrm{D}^{1}$
}

${ }^{1}$ Veterinary Diagnostic Laboratory of Bolzano, Istituto Zooprofilattico Sperimentale delle Venezie, Via Laura Conti 4, 39100, Bolzano, Italy

${ }^{2}$ Public Veterinary Service, Azienda sanitaria dell'Alto Adige, Via Laura Conti 4, 39100, Bolzano, Italy

${ }^{3}$ Practitioner, Villa 105, 39058, Sarentino, Italy

${ }^{4}$ Provincial Veterinary Service, Provincia autonoma di Bolzano, Via Laura Conti 4, 39100, Bolzano, Italy

${ }^{5}$ Veterinary Diagnostic Laboratory of Treviso, Istituto Zooprofilattico Sperimentale delle Venezie, Vicolo Mazzini 4, 31012, Villorba di Treviso, Italy

${ }^{*}$ Corresponding author: Giulia Morosetti, Official Veterinary Service, Azienda sanitaria dell'Alto Adige, Via Laura Conti 4, 39100, Bolzano, Italy, Email: giulia.morosetti@sabes.it

Citation: Tavella A, Morosetti G, Caresia S, Ciavatta P, Trevisiol K, et al. (2014) Acute type C botulism with fatal consequences in a holstein breeding establishment in northern Italy. J Vet Sci Anim Husb 2(2): 202. doi: $10.15744 / 2348-9790.1 .502$

Received Date: July 21, 2014 Accepted Date: August 25, 2014 Published Date: August 28, 2014

BOTULISM is a neuro-paralytic intoxication illness caused by the ingestion of neurotoxins of Clostridium botulinum with contaminated water or food [1]. The Gram-positive spore-producing bacterium Cl. botulinum is found worldwide and can survive in spore form for up to 30 years in numerous substrates in the environment [2-4]. Cl. botulinum is classified into 7 or 8 different types $\left(\mathrm{A}, \mathrm{B}, \mathrm{C}\left(\mathrm{C}_{1}, \mathrm{C}_{2}\right), \mathrm{D}, \mathrm{E}, \mathrm{F}, \mathrm{G}\right)$ depending on the antigen properties of the botulinum neurotoxins (BoNT) produced, with intoxication mostly appearing in cattle following the ingestion of neurotoxins of type $\mathrm{C}$ and $\mathrm{D}$ and, less frequently, of type $\mathrm{B}$ [5-9]. The clinical signs are caused by highly specific neurotoxins that inhibit the release of neurotransmitters by exocytosis, leading to paralysis $[1,2,5]$. Neurotoxins can enter feed via toxin-containing rotting animal carcasses $[5,10,11]$ or be produced directly via the primary growth of $\mathrm{Cl}$. botulinum in protein-rich substrates in favourable conditions (temperature between $25^{\circ} \mathrm{C}$ and $30{ }^{\circ} \mathrm{C}$, $\mathrm{pH}$ value $>4.5$, anaerobiosis) [6,12]. Botulism cases in cattle are also linked to contamination of feed by poultry litter [13-16].

\section{Case report}

\section{History}

We describe a severe outbreak of acute botulism in a small Holstein-Friesian breeding herd located in the Autonomous Province of Bolzano (Northern Italy). On $26^{\text {th }}$ September 2013 the farm veterinarian reported the case of a downer cow presenting symptoms ascribable to hypocalcaemia.

The animal was recumbent, with the head in self-auscultation position. Treatment for milk fever proved useless and the cow died the next day. Two other cows with similar symptoms were found lying down over the next two days. The number of affected animals peaked on the sixth day after the first case described. In total, 14 cows showed symptoms of acute intoxication that ultimately led to death.

The Holstein-Friesian breeding herd is part of a typical mountain farm with a cowshed where the lactating cows are kept together with dried-off cattle, heifers and calves.

The feed ration of the cows consists of a hay and grass silage mixture produced on the farm, as well as a commercial concentrated feed mixture in pellet form. The heifers are provided with unlimited hay and also get the uneaten food from the feed table for the cows each day; the calves are fed fine hay and small amounts of concentrated feed.

Adjacent to the cowshed there is a smaller enclosure where eight hens are kept. There is however no direct contact between the cattle and the chickens.

The responsible veterinarian reported also occasional mortality in postpartum cows during the winter months 2013. In these cases no diagnostic specimens were submitted for laboratory investigation. The clinical signs (recumbency, inappetence, and fatigue) were linked to acute hypocalcaemia.

During the period of the botulism outbreak 13 cows (11 in lactation), 3 heifers and 4 calves were kept in the cowshed. Four more heifers were kept on summer pastures, thus had no contact with the other farm animals. 


\section{Clinical signs}

The symptoms generally showed a rapid development that led within a few days either to the death or the euthanasia of the affected animals.

In the initial phase the general condition of the animals was negatively affected to differing degrees. On the first day of illness most cows showed progressive weakening of the hind limbs, swaying while standing and clear difficulty in standing up, a decline in milk production, inappetence, difficulty in swallowing and severe salivation. Within 24 hours of the onset of symptoms the animals showed general paralyses, lying down first on the knees, sometimes swinging the head, and finally lying on the side. Further neurological symptoms determined in all animals were decreased tongue tonus, reduced sensitivity, mydriasis, flaccid paralysis of the tail, shallow breathing and impaired rumen motility. The outbreak lasted in total 10 days, during which 12 animals (10 cows, two heifers) died and two more (one cow, and one heifer) had to be euthanised for animal welfare reasons; two lactating cows and four calves survived the botulism outbreak (Table 1).

\begin{tabular}{|c|c|c|c|c|c|}
\hline & Number & $\begin{array}{c}\text { Animals with } \\
\text { symptoms }\end{array}$ & $\begin{array}{c}\text { Animals } \\
\text { dying }\end{array}$ & Morbidity (\%) & Fatality (\%) \\
\hline Cows & 13 & 11 & 11 & 85 & 100 \\
\hline Heifers & 3 & 3 & 3 & 100 & 100 \\
\hline Calves & 4 & 0 & 0 & 0 & 0 \\
\hline Total & $\mathbf{2 0}$ & $\mathbf{1 4}$ & $\mathbf{1 4}$ & $\mathbf{7 0}$ & $\mathbf{1 0 0}$ \\
\hline
\end{tabular}

Table 1: Number and age of the animals concerned as well as morbidity and fatality rates in relation to the botulism case described

\section{Pathology}

A pathological post-mortem examination was conducted on one cow. The pathological changes were limited to the gastrointestinal tract, where a clear hyperaemia of the mucosa in the abomasum and small intestine was observed. No other organic changes were detected.

\section{Materials}

Blood samples, as well as faecal samples were taken from the rectum of 5 cows presenting clinical signs. Diagnostic specimens of the different feeds (hay, grass silage, concentrated feed, and straw) were also collected. In the course of the pathological examination the following specimens were taken for laboratory examination from the necropsied animal: liver parenchyma, kidneys, contents of the rumen, omasum and abomasum, as well as the contents of the caecum and jejunum.

Since it was suspected that the breeder had mixed poultry litter with cattle dung in the spring and spread this on the fields in autumn, a general faecal sample was also taken from the henbarn floor.

\section{Methods}

1.5 grams of prestomach, abomasum, intestinal content and poultry litter was mixed with saline solution (V/V) and introduced in $12 \mathrm{ml}$ of fortified cooked meat medium (FCMM) [17]. The same medium was inoculated also with 1.5 grams of liver, kidney and concentrated feed. 500 grams of hay, grass silage, straw was washed with $500 \mathrm{ml}$ of saline solution. The solution was centrifuged 20 minutes (12.000 rcf) and 1 gram of the pellet was introduced in $9 \mathrm{ml}$ of FCMM.

Tubes inoculated with the samples were immersed in hot bath $\left(71^{\circ} \mathrm{C}\right)$ for 10 minutes, cooled in water and incubated at $37{ }^{\circ} \mathrm{C}$ in anaerobic chamber (Bactron IV, Shellab). After 48 hours, $175 \mu$ l of each broth was collected from the bottom of the tubes and DNA was automatically extracted (Microlab Starlet, Hamilton). For DNA extraction, the Mag Max Total Nucleic acid isolation kit (Ambion) was used. PCR protocols for type A, B, C, D, E and F Cl. botulinum neurotoxin genes was applied according with previously published protocols $[18,19]$.

Botulinum neurotoxin was investigated in serum samples by the mouse neutralization bioassay, as described by [20].

\section{Results}

Type C Cl. botulinum was detected in the 5 faecal samples and in the contents of the rumen, omasum, and abomasum, as well as in the contents of the caecum of the cow being necropsied. The type $\mathrm{C} \mathrm{Cl}$. botulinum was also detected in the grass silage and the poultry litter (general faecal sample taken from the henhouse). The PCR analysis for Cl. botulinum neurotoxin type A, B, D, E and F on the same sampling material was negative.

The PCR analysis however showed no traces of $\mathrm{Cl}$. botulinum in the concentrated feed, in the hay or straw, or in the liver, kidneys and jejunum contents of the cow subjected to pathology. Toxicological examination of blood samples by means of biological testing proved negative in all five cases (Table 2). 


\begin{tabular}{|c|c|c|}
\hline Material & Number & Cl. botulinum type C \\
\hline Cow faeces & 5 & Pos. \\
\hline Rumen & 1 & Pos. \\
\hline Omasum & 1 & Pos. \\
\hline Abomasum & 1 & Pos. \\
\hline Jejunum & 1 & Neg. \\
\hline Caecum & 1 & Pos. \\
\hline Liver & 1 & Neg. \\
\hline Kidney & 1 & Neg. \\
\hline Hay & 2 & Neg. \\
\hline Grass silage & 2 & Pos. \\
\hline Conc. Feed & 2 & Neg. \\
\hline Straw & 1 & Neg. \\
\hline Poultry litter & 1 & Pos. \\
\hline Neg., No laboratory proof of Cl. botulinum; Pos., Laboratory proof of Cl. \\
botulinum
\end{tabular}

Table 2: Results of PCR analysis of Clostridium botulinum

\section{Discussion}

The case of acute botulism described within this paper was observed in a Holstein dairy farm in the Autonomous Province of Bolzano. Thirteen cows, three heifers and four calves were kept together in a small cowshed; four heifers were being kept on summer pastures during the outbreak. Eight hens were kept in a specially designated area without access to the outside (noncaged), adjacent to the cowshed and with no direct contact between chickens and cattle. The grass silage, that was produced on the farm and in which the presence of type $\mathrm{C} \mathrm{Cl}$. botulinum was proven by means of PCR, was suspected to be the source of intoxication.

The high mortality rate mentioned above could have been linked to an infection with the mosaic type C/D or D/C, as these types seem to be more lethal for animals, genetically different from type C Cl. botulinum [21,22] and are extended in Europe. However, these types could not be detected in this study.

Moreover, it is not surprising that neurotoxin was not detected in sera of diseased animals by mouse test since it has rarely been traced in the blood of affected bovines [23-25]. This hypothesis could be explained by a higher sensitivity to BoNT of cows in comparison to mice.

The botulism diagnosis is generally based on the clinical signs, and on the proved presence of BoNT in the contents of the stomachs and digestive tracts of affected animals and in the suspected source of infection (e.g. feed). As it is often difficult to detect toxins, clinical findings assume great importance for the diagnosis of botulism $[1,2,12]$.

In the case described the suspected botulism diagnosis was based on the characteristic symptoms observed in the 14 affected animals. The neurological disorders identified through detailed examination of the animals were similar to those already discussed by other authors in cases of botulism in cattle $[1-3,6,8,11,12]$. Other toxigenic bacteria (e.g. Cl. perfringens, Salmonella) and food poisoning (e.g. Conium maculatum) with relevance in differential diagnosis terms were excluded on the basis of medical history, case history and pathological results.

In the 14 infected animals, the muscles of the hind limbs, the gullet (swallowing problems), the tongue and the tail (which showed clear flaccid paralysis) were particularly affected. Also striking were the severe salivation, persistent mydriasis, shallow breathing and impaired rumen motility. The symptoms described occurred in all 14 affected animals (11 cows and 3 heifers) to varying degrees, but always clearly and easily detectable. The most pronounced symptoms occurred in those cows that were fed the largest amount of grass silage. The heifers showed neurological disorders a few days later than the lactating animals and the degree of severity was lower than in the cows. Note that the younger animals were given the remains of the food from the feed table of the cows and it appears probable that the lower quantities of silage led to a lower toxin dose and thus less severe symptoms. The calves, which were only given hay and concentrated feed, were on the other hand not affected. The suspect silage was stored in a tower silo with a total of volume of $85 \mathrm{~m}^{3}$ consisting of dried grass (first mown in 2012) from the farm. There were problems regarding the quality (poor acidification, $\mathrm{pH}$ value $>4.5$ ) and storage of the silage (poor hygiene, and contamination with soil and sand). The use of heavy machinery and the excessively close mowing probably caused contamination of the grass with soil particles. The subsequent ensilage and inadequate acidification of the grass may have produced an ideal breeding ground for the growth of $\mathrm{Cl}$. botulinum and the production of BoNT. Although Cl. botulinum can occur worldwide in the environment [2,5], its distribution is not homogeneous. Many factors can cause the contamination and accumulation of $\mathrm{Cl}$. botulinum in the soil, including the use of 
manure from infected animals to fertilise meadows and pastures, thus releasing Cl. Botulinum [7], for example suspect contamination of the environment through the use of poultry litter as fertiliser. The spores of Cl. botulinum can survive for decades in the soil [2-4] and remain infectious. These spores are ingested orally with food and colonise the gastrointestinal tract, leading to the production of BoNT in anaerobic conditions [7]. BoNT is absorbed through the intestinal mucosa while Cl. botulinum and the toxins produced are then released via the faeces. This fact results in an increased threat of infection on the farm and greater contamination of the environment through the use of dung as fertiliser. The increase in the prevalence of Cl. botulinum in the soil also increases the risk of infection [4].

The proof of type $\mathrm{C} \mathrm{Cl}$. botulinum in the poultry litter sampled at the affected establishment, the fact that it was mixed with cow dung for use as fertiliser on the fields, as well as the simultaneous detection of soil and sand in the silage, could indicate that the basic feed was contaminated by type $\mathrm{C} \mathrm{Cl}$. botulinum (or maybe the related BoNT) from the poultry litter. It should also be noted that the attending veterinarian reported a number of deaths in cattle in the postpartum phase in the winter of 2013 . The clinical signs of recumbency and fatigue, diagnosed as symptoms of acute hypocalcaemia at the time, may have been caused by the ingestion of silage contaminated with type $\mathrm{C} \mathrm{Cl}$. botulinum. Faeces from diseased animals were also used as fertiliser on the fields during spring of 2013.

Botulism outbreaks caused by indirect or direct contamination of feed by poultry litter had already been presumed and described by several authors $[8,13,15,16,26,27]$. Other authors have described type C botulism in cattle that had been fed ensiled poultry litter as an additive, or cases where the animals had free access to poultry litter [28-30]. These reports seem to corroborate the suspected contamination, in the case reported here, of feed or soil via the poultry litter of infected hens (or dung from infected cattle). The affected cattle had no direct contact with the hens and their excrement.

Botulism in cattle was formerly only linked to the consumption of water or food contaminated by rotting carcasses [2]. Currently, scholars particularly emphasise the cause of botulism to be triggered by contamination of feed with soil and the unsatisfactory keeping of feed batches [12,31]. These hypotheses are of the outmost importance also for small farms in the Alpine regions. On the one hand it is common for different species of animals, including chickens, to be kept together in one multispecies farming structure. The manure from the various animals is mixed together and used as fertiliser on the pastures and fields. The carcasses of dead hens are also not infrequently thrown onto the dung heap to rot, further increasing the risk of contamination [8,27]. On the other hand, the cut grass is in many places only dried for a short time and then immediately ensiled due to the unstable weather prevailing in the Alps. The bad weather conditions of the last few years, as well as prolonged periods of rain in the summer months, have made it difficult to gather high-quality feed. The problems described also lead to the presumption that these are one of the causes of the occurrence of clostridiosis in grazing animals.

In recent years, in northern Italy, an increase in acute clostridioses has been observed, including an outbreak of botulism, in farm ruminants in the Autonomous Province of Bolzano, where for precautionary reasons the sale of milk was stopped as soon as the suspected botulism was detected (Morosetti, unpublished data). Although some studies did not find evidence that this toxin may be able to cross from blood to milk in detectable concentrations [5,8], type B BoNT has been identified in milk [32]. In addition, BoNT could be excreted in milk before the appearance of clinical symptoms [33]. Since BoNT is heat labile, pasteurisation of milk should eliminate any possible health risk. However, for public health reasons, no such risk should be taken and milk destruction is considered the safer management option, as underlined by [23].

The increase in cases of botulism in the Alps and in Europe in general, as well as the intensification of cattle breeding in the Alpine regions, require a rethinking of farm management and preventive measures in the use of fertilisers and the production of basic feeds. With this report we intend to provide a starting point for further investigation on $\mathrm{Cl}$. botulinum contamination of meadows and pastures through the use of untreated dung of infected animals as fertiliser.

\section{References}

1. Braun U (2006) Botulismus beim Rind. Schweizer Archiv für Tierheilkunde 148: 331-9.

2. Stöber M (2002) Botulismus In Innere Medizin und Chirurgie des Rindes (4 $4^{\text {th }}$ edn) Berlin, Parey Buchverlag Publishers, Germany $1113-9$.

3. Radostits OM, Gay CC, Hinchcliff KW, Constable PD (2007) Botulism In Veterinary Medicine A Textbook of the Diseases of Cattle, Sheep, Pigs, Goats and Horses $\left(10^{\text {th }} \mathrm{edn}\right)$ Saunders Elsevier, London 824-8.

4. Krüger M, Grosse-Herrenthey A, Schrödl W, Gerlach A, Rodloff A (2012) Visceral Botulism at dairy farms in Schleswig Holstein, Germany: Prevalence of Clostridium botulinum in feces of cows, in animal feeds, in feces of the farmers, and in house dust. Anaerobe 18: 221-3.

5. Galey FD, Terra R, Walker R, Adaska J, Etchebarne MA, et al. (2000) Type C botulism in dairy cattle from feed contaminated with a dead cat. J Vet Diagn Invest 12: 204-9.

6. Kelch WJ, Kerr LA, Pringle JK, Rohrbach BW, Whitlock RH (2000) Fatal Clostridium Botulinum Toxicosis In Eleven Holstein Cattle Fed Round Bale Barley Haylage. J Vet Diagn Invest 12: 453-5.

7. Böhnel H, Schwagerick B, Gessler F (2001) Visceral Botulism - A new form of bovine Clostridium botulinum toxication. J Vet Med A. Physio Pathol Clinil Med 48: 373-83. 
8. Moeller RB, Puschner B, Walker RL, Rocke T, Galey FD, et al. (2003) Determination of the median toxic dose of type C botulinum toxin in lactating dairy cows. J Vet Diag Invest 15: 523-6.

9. Senturk S, Cihan H (2007) Outbreak of botulism in a dairy herd in Turkey. Irish Vet J 60: 481-4.

10. Myllykoski J, Lindström M, Keto-timonen R, Söderholm H, Jakala J, et al. (2009) type c bovine botulism outbreak due to carcass contaminated non-acidified silage. Epid infect 137: 284-93.

11. Francione E, Paternolli S, Berasi G, Guella S, Toller G, et al. (2013) Episodio di botulismo in un allevamento di bovine da latte del Trentino Alto Adige: Un caso clinico. J Italian Assoc Buiatrics 8: 31-9.

12. Braun U, Feige K, Schweizer G, Pospischil A (2005) Clinical findings and treatment of 30 cattle with botulism. Vet Rec 156: 438-41.

13. Smart JL, Jones TO, Clegg FG, Mcmurtry MJ (1987) Poultry waste associated type C botulism in cattle. Epi Infec 98: 73-9.

14. Anon (2006) Guidance for farmers on preventing botulism. J British Vet Asso 159: 827.

15. Otter A, Livesey C, Hogg R, Sharpe R, Gray D (2006) Risk of Botulism in cattle and sheep arising from contact with broiler litter. Veter Rec 159 : 186-7.

16. Kennedy S, Ball H (2011) Botulism in cattle associated with poultry litter. Vet Rec 168: 638-9.

17. Kurazono H, Shimozawa K, Sakaguchi G, Takahashi M, Shimizu T, et al. (1985) Botulism among penned pheasants and protection by vaccination with C1 toxoid. Res Vet Sci 38: 104-8.

18. Medic DD, Anniballi F, Wyatt GM, Lindström M, Messelhäusser U, et al. (2009) Multiplex PCR for detection of botulinum neurotoxin-producing clostridia in clinical, food, and environmental samples. Appli Envi Micr 75: 6457-61.

19. Woudstra C, Skarin H, Anniballi F, Fenicia L, Bano L, et al. (2012) Neurotoxin gene profiling of clostridium botulinum types C and D native to different countries within europe. Appl Enviro micro 78: 3120-7.

20. Gimenez DF, Gimenez JA (1995) The typig of botulinal neurotoxins. Int J Food Micro 27: 1-9.

21. Takeda M, Tsukamoto K, Kohda T, Matsui M, Mukamoto M, et al. (2005) Characterization of the neurotoxin produced by isolates associated with avian botulism. Avian Diseases 49: 376-81.

22. Skarin H, Lindberg A, Blomqvist G, Aspàn A, Båverud V (2010) Molecular characterization and comparison of Clostridium botulinum type C avian strains. Avian Pathology 39: 511-8.

23. Cobb SP, Hogg RA, Challoner DJ, Brett MM, Livesey CT, et al. (2002) Suspected botulism in dairy cows and its implications for the safety of human food. Vet Rec 150: 5-8.

24. Hogg R, Livesey C, Payne J (2008) Diagnosis and implications of botulism. In Practice 30: 392-7.

25. Lindström M, Myllykoski J, Sivelä S, Korkeala H (2010) Clostridium botulinum in cattle and dairy products. Crit Rev Food Sci Nutr 50: 281-304.

26. Ortolani EL, Brito LA, Mori CS, Schalch U, Pacheco J, et al. (1997) Botulism outbreak associated with poultry litter consumption in three Brazilian cattle herds. Vet Human Toxi 39: 89-92.

27. Payne JH, Hogg RA, Otter A, Roest HI, Livesey CT (2011) Emergence of suspected type D botulism in ruminants in England and Wales (2001 to 2009), associated with exposure to broiler litter. Vet Rec 168: 640.

28. Mcloughlin MF, Mcilroy SG, Neill SD (1988) A major outbreak of botulism in cattle being fed ensiled poultry litter. Vet Rec 122: 579-81.

29. Neill SD, Mcloughlin MF, Mcilroy SG (1989) Type C botulism in cattle being fed ensiled poultry litter. Vet Rec 124: 558-60.

30. Jean D, Fecteau G, Scott D, Higgins R, Quessy S (1995) Clostridium botulinum type C intoxication in feedlot steers being fed ensiled poultry litter. Can Vet J 36: 626-8.

31. Böhnel H, Gessler F, Bostedt H (2013) Presumptive Diagnostic of an Intrauterine Transmission of Clostridium Botulinum in a Bovine Fetus. Int J Vet Med doi: $10.5171 / 2013.747291$.

32. Böhnel H, Neufeld B, Gessler F (2005) Botulinum neurotoxin type B in milk from a cow affected by visceral botulism. Vet J 169 : $124-5$.

33. Moberg LJ, Sugiyama H (1980) The rat as an animal model for infant botulism. Infect Immun 29: 819-21.

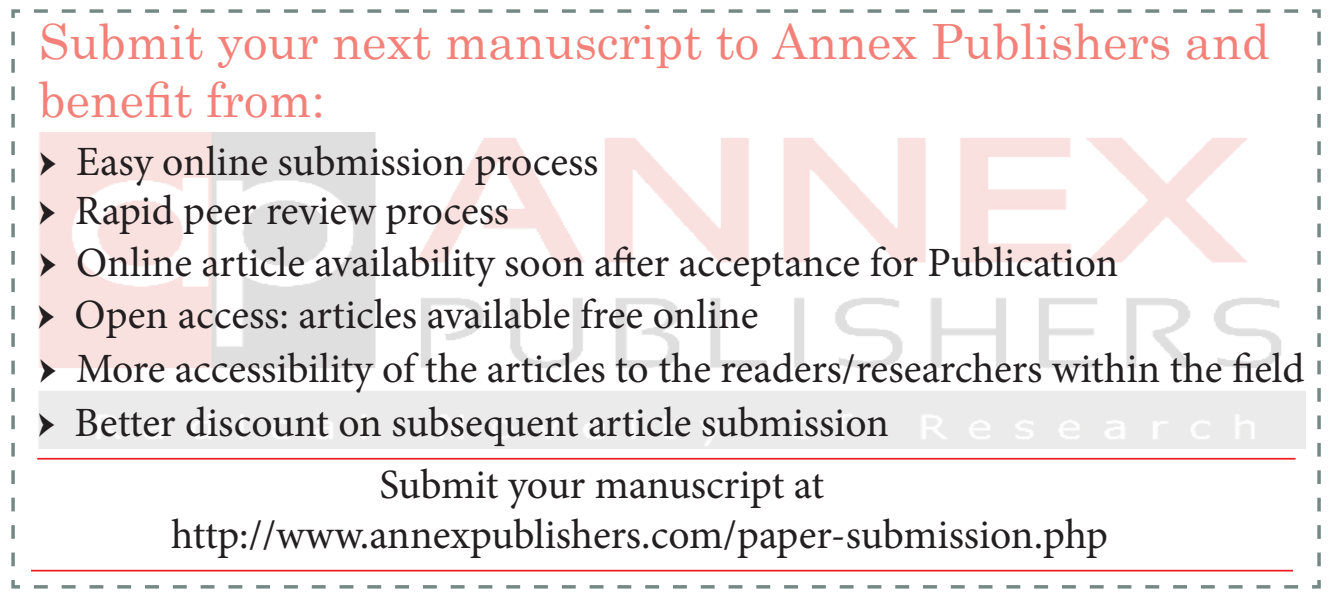

